\title{
Evaluation of the Effectiveness of Course Integrated Library Instruction in an Undergraduate Nursing Program 1
}

\author{
Alison Farrell, Janet Goosney, and Karen Hutchens
}

\begin{abstract}
Introduction: Many faculty in two Schools of Nursing found that students in the fourth year of the Bachelor of Nursing program were not well equipped to perform information literacy activities efficiently and effectively, such as doing research to support their daily work. A course-integrated information literacy program was implemented at both sites, which left some students having very little information literacy training, whereas others who started the program in later years had information literacy training in all or most years of the curriculum. This study sought to evaluate students as they gained more experience with information literacy. Methods: To determine if increased exposure to information literacy training improved students' levels of competency and confidence, the authors compared first-year students with two groups of fourth-year students who had differing exposures to information literacy. Results: Acceptable response rates for data analysis were acquired at only one site. It was found that overall, fourth-year students were more confident and tested better with information literacy competencies than first-year students, but there was not as much improvement as was hypothesized. Discussion: The results of this evaluation have demonstrated a need to improve the information literacy teaching in certain areas. The data have also indicated that students do indeed retain information literacy skills with an increased number of sessions. Further areas for study are outlined as well as the limitations and strengths of the study design.
\end{abstract}

\section{Introduction}

In a world where vast amounts of health-related information are produced, information literacy (IL), the ability to "recognize when information is needed and have the ability to locate, evaluate and use effectively the needed information" [1], is a necessary skill for nurses. To be information literate, a nurse must be able to define exactly what he or she needs to know, select the most appropriate resources to answer those questions, find the information efficiently, evaluate it to make sure it is the right information for that situation, and finally use the information in an ethically responsible way. These skills are increasingly required of nursing graduates [2] and should be learned well before they enter into a patient care setting.

This paper examines a curriculum-integrated, multiyear information literacy program offered to Bachelor of Nursing (BN) students at two Memorial University sites, both located in St. John's, Newfoundland. It focuses on an outcomes-based plan of assessment that was used to evaluate the program as it was phased in over a four- year period. Designs of the assessment instrument are discussed, along with results at one site. Challenges and recommendations to be considered when engaging in this kind of long-term evaluation are reviewed.

\section{Literature review}

For many years, librarians have been giving one-shot information literacy sessions to students, but there is evidence that the information taught in these one-time sessions is not retained long term. The old adage of "use it or lose it" seems to ring true when applied to information literacy, with research showing that IL skills taught in oneshot sessions are often not retained and carried forward into subsequent semesters [3-5].

Carlock and Anderson sought to evaluate IL skills using performance-based assessments [6]. They found that students who received only one IL session scored lower on their assessments over time than did their counterparts who continued to receive IL sessions through the course of their program. Lalor, Clarke, and Sheaf found that IL

Alison Farrell ${ }^{2}$. Health Sciences Library, Memorial University of Newfoundland, St. John's, NL A1B 3V6.

Janet Goosney. Queen Elizabeth II Library, Memorial University of Newfoundland, St. John's, NL A1B 3Y1.

Karen Hutchens. Learning Resource Centre, Southcott Hall, 100 Forest Road, St. John's, NL A1A 1E5.

${ }^{1}$ This article is peer reviewed.

${ }^{2}$ Corresponding author (e-mail: alisonr@mun.ca). 
training in the first and second years of a midwifery undergraduate program improved post-test scores, but further training in the third year did not contribute to greater knowledge gain [7]. By contrast, Jacobs, Rosenfeld, and Haber, who assessed a program involving IL modules taken throughout the curriculum, found that test scores continually improved with the completion of each module [8]. Although it is true that one-shot sessions can be useful in the short term, little evaluation has been done with this type of IL over longer periods [9]. It is felt that IL should be at the point of need $[5,10]$, should mirror real world situations [5], and should be spread out over an entire curriculum with each session building on the previous lessons [5]. It is also felt that graded work will increase the retention of IL skills [6]. However, incorporating a series of IL sessions into an already full curriculum has its challenges. Not all faculty members teaching each particular course will want to include an IL component. This means that as the teaching faculty change, the inclusion of IL may change as well. It is therefore imperative to gain faculty support and to ensure they understand the importance of IL for their students. Once a curriculumintegrated program is implemented, it is also important to incorporate measures of evaluation. As Kroth, Phillips, and Eldredge point out, this can be difficult due to the ever-changing nature of health care and therefore the necessity for health related curricula to change rapidly [11]. With changing curricula, it is hard to be consistent in what and how IL skills are taught.

Although there have been a large number of studies evaluating the information literacy skills of nursing students, most have been conducted in Australia, New Zealand, Asia, the United Kingdom, and the United States. According to Brettle, who published a systematic review looking at health library related IL evaluations, only three studies were found in Canada and these were either conducted in the clinical setting or with medical and dental students [12].

Of the IL evaluation studies that have been published, many different methods were employed. The most common method of evaluation seems to be the use of pre- and posttests [7, 8, 13-19]. Studies using pre- and post-tests found that there was overall improvement in IL knowledge after students received the training $[7,8,13,14,17,19]$. In some cases, however, the improvement was found to be marginal $[13,19]$. Another method is the use of different cohorts. One study tested five different cohorts of medical students who received varying levels of IL [9]. It was found that although all of the students remembered their IL sessions, those with more training showed that they could expand on the skills they had learned. Cullen, Clark, and Esson assert that this shows that IL training provides valuable skills and contributes to lifelong learning [9]. Another study looked at occupational therapy students with some or almost no IL training [20]. Other studies used performance-based assessments [6] or portfolios [21] as a method of evaluating actual IL skills. Lastly, one study was found that did a oneshot survey of students who took an IL class [22].

Of the evaluation studies found, most looked at students' levels of comfort or confidence in their IL skills. The research from these studies was not conclusive and the findings were often contradictory. A number of authors found that many students are overconfident in their IL knowledge; when surveyed for both levels of confidence and actual ability, students rated themselves as having a good understanding of IL, but the questions that actually tested their knowledge or abilities showed that they lacked IL skills $[9,18,23,24]$. Conversely, students who performed well had a tendency to underestimate their skills [23]. Others also found low confidence levels with regards to IL when surveying students [15, 22, 25]. Many studies found that confidence levels increased as the amount of IL training increased [13, 16, 17, 19, 26], but one landmark study by Verhey in 1999 found that confidence levels did not increase with increased exposure to IL [15]. Verhey postulates that this may be because as students' exposure to IL training increased, their knowledge of the vast amounts of information also increased and so they realized that "the more you know, the more you know what you do not know".

One of the unique features of the IL programs at Memorial is the exposure to searching principles for evidence informed practice (EIP), the "continuous interactive process involving the explicit, conscientious and judicious consideration of the best available evidence to provide care" [27]. No studies were found that evaluated undergraduate nursing students' IL skills in the area of EIP. Those studies that did look at IL skills in EIP examined students at the graduate level [8, 23], post-registration nurses returning to university to receive their BNs [16], occupational therapy students [20], or medical students [9].

\section{Background}

Memorial University of Newfoundland is the largest University in Atlantic Canada. It offers a BN program through the School of Nursing located at the Health Sciences Centre (HSC). The Centre for Nursing Studies (CNS), operated under the Eastern Health Authority, was formed in 1996 when several separate nursing schools in St. John's were amalgamated. The CNS offers a BN program in conjunction with Memorial University. All nursing students are Memorial students and are granted degrees from Memorial University.

Until 2008, nursing students at the HSC received a oneshot information literacy class in their first semester. This class was designed to teach them about database searching, different types of literature (scholarly vs. popular), website evaluation, and some of the details of American Psychological Association citation style, all in a single one- to two-hour session. Students at the CNS received only a brief introduction to the library during their orientation week. Anecdotal information from nursing professors indicated that these sessions were not adequate and that $\mathrm{BN}$ students were not finding appropriate materials for their research papers. The general consensus between instructors and librarians was that students would benefit from information literacy instruction sessions in all years of the nursing curriculum and that each session should build on the skills previously learned.

In the fall of 2008, a new program was implemented at the HSC in which BN students receive IL instruction in the 
first, second, and third years of the nursing curriculum. This change was brought about through a proposal developed by one of the researchers that mapped specific IL skills to the objectives of the nursing curriculum. The following outlines what is taught in each year of the curriculum:

First Year: basic searching of the Cumulative Index for Nursing and Allied Health Literature (CINAHL) database, and evaluating and distinguishing between popular and scholarly literature.

Second Year: drug information resources, alternative medicine resources, critical evaluation of web-based information, and advanced CINAHL searching techniques (subject headings).

Third Year: the principles of evidence informed practice, study types, formulating a research question using the PICO (patient, intervention, comparison, outcome) method, searching PubMed using both MeSH and clinical queries, searching CINAHL using clinical queries, and other evidence-based resources (UptoDate, Dynamed, etc.)

Each IL session has an assignment designed to encourage reflection and to reinforce the knowledge and skills learned in that class. All assignments are marked by a librarian and range from $5 \%-15 \%$ of the student's final mark in a particular course.

The embedded information literacy program began at the CNS in the winter of 2009. It followed the same set of classes and assignments as the program at the HSC with a few minor modifications. These modifications were made to allow as many students as possible to receive the IL sessions. The second-year students received the CINAHL instruction they would normally have received in first year, and the fourth-year students received the PubMed and PICO instruction that was taught in third-year classes at the HSC site.

To evaluate the success of the cumulative, curriculumintegrated information literacy program at the HSC, the researchers developed an outcomes-based plan of assessment. This assessment plan was designed to be administered to each graduating class over a four-year period. Because the IL program was implemented for all classes at once, this would allow for comparison of students with different levels of exposure to the program, from those in the initial year of assessment who had received only the original one-shot class to those in the last year of assessment who have engaged in all phases of the new program. This evaluation was later adopted at the CNS. Owing to the modifications in timing of the IL sessions, it was necessary to employ a different study method using the same assessment tool.

\section{Design}

Following the implementation of the new IL program at the HSC in the fall of 2008, two librarians partnered to develop a plan of assessment. The first step was to identify the kinds of evidence that needed to be gathered. As a result, a project purpose was articulated, followed by specific research goals.

Purpose: To evaluate the success of a new cumulative, curriculum-integrated IL program for undergraduate nursing students, by comparing the IL skills of graduating students over the four-year program-implementation period.

Goals: $(i)$ to test the confidence and (or) empowerment of students with regards to information literacy skills, (ii) to test the actual ability and (or) learning of those skills, and (iii) to test the effectiveness of the cumulative, curriculum-integrated instruction model.

As a result of goals $(i)$ and (ii), the researchers took a dual approach to evaluation. Some questions were designed to evaluate students' confidence in their own information literacy skills and their comfort with evidence-informed practice, whereas others provided evidence of actual learning. Research on cognitive bias has demonstrated that unskilled individuals frequently over-estimate their ability at a given task, a phenomenon that has come to be known as the "Dunning-Kruger effect" [28-30]. Melissa Gross and Don Latham have found evidence of the Dunning-Kruger effect among undergraduates when asked to self-assess their information literacy skills [31,32].

To address concerns about the Dunning-Kruger effect, the majority of evaluation questions were outcomes-based, designed to test actual student learning in a number of identified areas. To develop these questions, the researchers started by examining the learning outcomes for the new nursing IL program (Table 1). Fourteen questions were created, each one designed to test one or more outcomes (for a complete list of questions see Appendix A). A variety of question formats were used (e.g., multiple choice, question matrix, short answer), depending on the nature

Table 1. Learning outcomes for the $\mathrm{BN}$ information literacy program, with corresponding test questions (numbers based on the Fall 2011 questionnaire).

Outcome: As a result of the BN information literacy program, students will be able to .. Corresponding question(s)

formulate a searchable question. understand different study types, and to know when each is appropriate.

find information in health related databases (CINAHL, PubMed, etc.).

$12,13,19$

understand the process of doing an effective and efficient literature search.

$9,11,14$ appraise and revise search strategies.

$6,7,19$

All

find information on natural products, and alternative and complementary medicine.

7,19

identify various drug information sources for professionals and the general public. 
of the question and to create some variety within the instrument.

Test design is a challenging process, and given that the goal of the project was to develop a long-term study in which data could be compared over a four-year period, it was important to ensure that any problems with question design be identified and fixed prior to implementation as the content of the questions could not be changed or adjusted following its initial distribution. For this reason, the researchers adopted three strategies to ensure the efficacy of the instrument.

\section{Drawing on in-house expertise}

The first strategy was to seek out expertise in test design. That expertise was readily available via the Instructional Development Office (IDO), a resource that provides support to Memorial University faculty for the enhancement of their teaching knowledge and skills [33]. Advice received from the IDO led to a number of improvements in the instrument, including clarification and rewording of some questions. The IDO also assisted with classifying each outcomes-related question in terms of the demonstrated type and level of learning so that they could be reordered in increasing order of difficulty.

\section{Question classification}

To evaluate the relative difficulty of the outcomes-based questions, each one was classified according to Bloom's Taxonomy. Because all questions tested some aspect of knowledge, understanding, or critical thinking, classification was based purely on the cognitive domain [34]. By classifying the questions, the researchers were able to identify the level of cognitive engagement required to successfully complete the questionnaire.

Of the test-type questions posed, six engaged respondents in lower-order, concrete cognitive activities, such as knowledge recall and comprehension. Eight questions challenged students to use higher-order skills such as analysis, synthesis, and critical evaluation. The largest proportion of higher-order questions required respondents to engage in analysis, level four of Bloom's six-tiered cognitive domain. This is not surprising, given that research is a pedagogical activity often associated with the fourth level.

By examining the questions through the lens of Bloom's Taxonomy, it was determined that the questionnaire provided an accurate measure of learning by engaging students at an appropriate cognitive level. To respond to all questions successfully, students needed to demonstrate basic knowledge but also move beyond simple recall to exhibit the higher-level skills that characterize information literacy, such as critical evaluation and analysis.

At the advice of the IDO, questions were reorganized to guide respondents "up the cognitive ladder", starting with simpler questions and gradually moving toward more complex, high-order skills. The expectation was that this would encourage students to complete the questionnaire by helping them to "warm up" to the more demanding questions. It was also hoped that the further respondents progressed, the more committed they would feel to completion.

\section{Usability testing}

After the questionnaire had been drafted and classified, an online version was created using Survey Monkey. The next step was to test both the usability of the online instrument and the clarity of the questions. This step marked the beginning of the collaboration between the HSC and the CNS in the area of IL assessment. With the help of the CNS librarian, four volunteers were identified from among the CNS graduating class to help test the instrument. CNS students were chosen for testing, as opposed to HSC students, because although they had comparable knowledge and experiences, these CNS students were not among the group who would be asked to complete the questionnaire. To recruit testers, an email was sent to students explaining the project and offering a small incentive of $\$ 10.00$ to those who were willing to volunteer their time.

Each tester was met individually and was asked to work their way through the instrument with a researcher observing, making notes, and occasionally asking questions. Testers were encouraged to comment on anything that they found confusing or misleading. They were timed as they worked their way through the questionnaire to help determine an average time for completion. No changes were suggested as a result of usability testing; however, testers did complete the questionnaire more quickly than originally estimated.

\section{Methods}

Although the evaluation was conducted at both the HSC and the CNS, response rates were extremely low at the HSC providing nonrepresentative samples; therefore, only CNS methods and results were examined. Due to modifications in the timing of the IL sessions in the 20092010 school year, it was necessary to administer the survey using a different method than had originally been planned for the HSC.

The embedded IL program at the CNS began in 2009, but the evaluation of the program began in the fall of 2010. At the CNS, students in their first year completed the survey as well as students in their fourth year. The goal was to compare answers from first-year students with answers from fourth-year students. The survey was given as a pretest to the classes of 2014 and 2015 (first-year students) prior to their first IL class. The survey was also given to the class of 2011 (fourth-year students) after they had completed years one and two of the IL program and to the class of 2012 (fourth-year students) after they had completed years one, two, and three of the IL program.

In contrast to the original method at the HSC using an online survey, the instrument was disseminated to students in class as a paper questionnaire. Students were given 20 minutes to complete the survey, but participation was not mandatory.

Two librarians graded the survey using an agreed upon rubric. Unclear responses were marked using consensus between the two librarians. 


\section{Results}

\section{Responses - Centre for Nursing Studies}

Four hundred and twenty-two responses were received from the CNS. A breakdown by year can be found in Table 2. Because of the differing exposures to IL training, the four surveyed groups were further refined to three cohorts (Table 2).

\section{Confidence levels}

When asked how prepared they felt to begin evidenceinformed practice, $68.3 \%(n=75)$ of the class of 2011 felt somewhat or very prepared while $78.5 \%(n=77)$ of the class of 2012 felt somewhat or very prepared. As expected, the first-year classes did not feel very prepared with only $33.3 \%(n=72)$ answering somewhat or very prepared to begin evidence-informed practice.

Next, the students were asked how confident they felt in their ability to perform specific tasks; the results can be seen in Table 3.

\section{Information Literacy Skills}

When asked to identify appropriate tools for locating scholarly research articles, a large increase in correct answers was seen among the three cohorts. Only $2.8 \%$ $(n=6)$ of the first-year students were able to correctly identify two appropriate resources. This percentage increased to $33.9 \%(n=37)$ for the class of 2011 and $57.1 \%(n=56)$ for the class of 2012 .

In a group of questions that examined whether students could make appropriate decisions about the use of scholarly and popular literature, there was improvement overall between the first-year cohort and the two fourthyear cohorts. For example, when asked what type of literature one should use to help a patient better understand his or her condition, $29.6 \%(n=64)$ of the first year students answered the question correctly, whereas $53.2 \%$ $(n=58)$ and $48 \%(n=47)$ of the classes of 2011 and 2012 , respectively, answered correctly.

Several questions focused on the students' ability to understand, identify, and evaluate study types and search results. Students at all levels had some difficulty in choosing types of studies (cohort, randomized controlled trial, cross sectional, case control) as part of their evaluation of search results. Only $9.7 \%(n=21)$ of the first-year students, $14.7 \%(n=16)$ of the class of 2011 , and $12.2 \%(n=12)$ of the class of 2012 were able to correctly identify the definition of a cross sectional study. However, students in the two fourth-year cohorts did significantly better $(41.2 \%(n=45)$ of the class of 2011 and $49 \%(n=48)$ of the class of 2012) than the first year cohort $(6.9 \%(n=15))$ when asked what kind of study they should look for to answer a therapy question. Similarly, when asked to determine question type for a given question, students from the class of 2012 showed the highest percentage of correct answers with $70.4 \%(n=69)$ answering correctly as opposed to $19.9 \%(n=43)$ of the first-year students and $62.3 \%(n=68)$ of the class of 2011 .

The students were also asked several questions about PICO. They were given a scenario and asked to pick out the appropriate PICO components. No students in the firstyear classes or in the class of 2011 got all four components right, whereas $11.2 \%(n=11)$ of the class of 2012 were able to correctly identify all four PICO components. Similarly, only three first-year students $(1.4 \%)$ and one student $(0.9 \%)$ in the class of 2011 were able to correctly identify any of the PICO components, whereas $32.7 \%(n=32)$ of the class of 2012 were able to identify one or more components. Next, students were asked to create an answerable question from the PICO components identified in the previous question. The fourth-year cohorts did slightly better with this question, with $11.9 \%(n=13)$ of the class of 2011 and $11.2 \%(n=11)$ of the class of 2012 writing an acceptable question. Only $3.7 \%(n=8)$ of the first-year cohort came up with an appropriate question.

Students were asked to identify three criteria for evaluating websites. Again, the fourth-year students performed better at this task, with $28.4 \%(n=31)$ and $30.6 \%$ $(n=30)$ of the classes of 2011 and 2012, respectively, providing three correct answers, compared with only $8.3 \%$ $(n=18)$ of first-year students.

For the final question, students were given a research question and four possible search statements. They were asked to select the search statement that would produce the

Table 2. Cohorts and amount of IL received (CNS).

\begin{tabular}{lcl}
\hline Cohort & Students in cohort (no.) & IL sessions attended \\
\hline Class of 2011 & 109 & Sessions meant for first and second year \\
Class of 2012 & 98 & Sessions meant for first, second, and third year (all) \\
Classes of 2014 and 2015 & 215 (98 and 117, respectively) & None (will eventually receive all) \\
\hline
\end{tabular}

Table 3. Confidence in specific skills*.

\begin{tabular}{|c|c|c|c|c|c|c|}
\hline & \multicolumn{2}{|c|}{ First year students } & \multicolumn{2}{|c|}{ Class of 2011} & \multicolumn{2}{|c|}{ Class of 2012} \\
\hline Reading research & $73.1(n=158)$ & $26.4(n=57)$ & $12.7(n=14)$ & $86.4(n=95)$ & $78.6(n=77)$ & $21.4(n=21)$ \\
\hline Searching for evidence & $51.9(n=112)$ & $48.1(n=104)$ & $30.0(n=33)$ & $70.0(n=77)$ & $57.1(n=56)$ & $42.8(n=42)$ \\
\hline Identifying research types & $41.7(n=90)$ & $57.9(n=125)$ & $39.1(n=43)$ & $60.9(n=67)$ & $58.2(n=57)$ & $41.8(n=41)$ \\
\hline
\end{tabular}

*"Not at all confident" and "not quite confident" were combined into the "Not confident" column. "Somewhat confident" and "very confident" were combined into the "Confident" column. 
best results; $28.4 \%(n=31)$ of the class of 2011 and $27.6 \%$ $(n=27)$ of the class of 2012 correctly identified the best search statement, whereas only $20.8 \%(n=45)$ of firstyear students correctly identified the best statement.

\section{Discussion}

Overall, the results showed improvements in skills from first to fourth year, but not as improved as the anecdotal information from faculty would indicate. Faculty reported that students no longer come to them with complaints that there isn't any information on the topic they have been given to research, instead recognizing that they have to go back and look again at their search terms. Faculty also reported that student papers had improved. Finally, faculty continue to devote class time for IL sessions each semester, indicating recognition of their value. Indeed, other course instructors have asked to supplement the core content of the IL program with additional, course-specific IL instruction.

As expected, the class of 2012 felt more prepared than the class of 2011 or the classes of 2014 and 2015 to begin evidence-informed practice, but when looking at individual skills, the reported confidence levels were surprising. When asked to rank their confidence in their ability to perform research actions, confidence levels rose between first-year students and the class of 2011 but decreased between the class of 2011 and the class of 2012. It was expected that the class of 2012 would be the most confident as they had received the most IL classes. This may be explained by the thinking "the more you know, the more you know you do not know".

The results of the cross-sectional study definition question were disappointing and indicated that perhaps more time needs to be spent examining study types. For other questions involving study designs and question types, material covered in the third year of the curriculum, the class of 2012 had higher percentages of correct answers than the other two cohorts. This was expected because they had more IL instruction in that area.

At the time of taking the survey, the class of 2011 had not yet received the IL session on using PICO and searching for evidence, whereas the class of 2012 had. As expected, neither the first-year students nor the class of 2011 could answer the PICO questions but unexpectedly, the class of 2012 did not perform well on these questions either, although they did show some improvement. It is unclear why these results were received, but they indicated that more time should be spent on defining the PICO components and designing an answerable question.

Evaluating websites is taught in the second year of the curriculum so both the classes of 2011 and 2012 would have received instruction in this area, whereas the first-year students would have not. The results of the questions relating to website evaluation were, therefore, not surprising with an increase being seen between the first-year cohorts and the fourth-year cohorts and no real increase between the two fourth-year cohorts.

The last question tried to force students to think about search strategies in a different way by asking them to choose the strategy that would give the most relevant results for a sample research question. There was some improvement between the first-year students and the fourth-year students, but the fourth-year students still did not perform well on this question. This was a particularly challenging question, because students were being asked to "reverse their thinking" about the rules of searching; this may partially explain the low performance at all levels. However, poor performance also suggests that more focus needs to be placed on defining the search components, questions, and search strategy, reinforcing the conclusions from the PICO questions.

\section{Limitations}

There were a number of challenges and limitations that arose throughout the course of this research, the largest of which was the response rate from the HSC. A number of factors may have contributed to this including the method by which the instrument was disseminated. At the HSC, the survey was distributed via email rather than in class as it was at the CNS.

Over the course of the study, researchers at the HSC employed a number of strategies to try to promote and increase participation. For example, prizes (a nursing watch and gift card for uniforms) were selected based on consultations with students and were advertised to all potential participants. Despite positive reassurance from students regarding the prize selections and their motivation factor, the response rate did not increase significantly.

One limitation encountered with the CNS methodology was that when analyzing survey responses, it appeared students might have worked together as some answers were suspiciously similar to those next to them in the paper pile. Also, although it was communicated to students that participation in the survey was not mandatory, because it was administered in class students may have felt pressured to participate.

A desire to test the learning outcomes thoroughly may have, in fact, contributed to the low response rate at the HSC due to both the length of the instrument and the challenging nature of some questions. A better approach might have been to create a shorter survey with a limited number of questions; to cover all learning outcomes, each student could be given a random selection of three or four questions from a complete list.

No statistical analysis was performed on the results, leaving only descriptive statistics. Although this may not be a disadvantage in itself, statistical significance of results cannot be claimed.

Lastly, this survey was specific to the course-integrated curriculum at the Memorial University of Newfoundland School of Nursing and the Centre for Nursing Studies, so results may not be widely generalizable.

\section{Future Directions}

As this research has been ongoing for just over four years, many potential directions have been discussed for future research opportunities and ways to improve the information literacy component of the Bachelor of Nursing degree program. Perhaps most significantly, lessons have been learned that will direct the program in the next few years. The results have indicated that more focus needs to be placed on defining the search problem, identifying 
appropriate PICO components, and designing applicable search strategies. Although qualitative analysis was not performed on the survey comments, a few general themes stood out. It would seem that students place a great deal of value on the IL sessions, but would like to see them happen earlier in the curriculum and more at the point of need. Efforts will be made to adjust the program accordingly.

A possible next step in this research process might be to perform pre- and post-tests on students at the HSC, preferably in the classroom, to maximize response rates. At the CNS, students were given unique identification numbers when completing the surveys so that it would be possible to survey the first-year students again when they are in fourth year, to see if individual marks improve as they receive more IL instruction. Further investigation in this area might potentially yield interesting results.

Given all of the anecdotal evidence heard from faculty members suggesting that increased IL results in better papers and more confident students, it would be interesting to hold focus groups with faculty members to obtain formalized qualitative information on their perceptions of student skills in the area of IL.

\section{Conclusion}

At the outset of implementing a curriculum integrated multiyear information literacy program into a $\mathrm{BN}$ degree program, it is vitally important to plan for the assessment of said program. A multiyear study was designed and implemented aiming to show that as students had more IL instruction, their confidence and actual skills would improve. From the results presented, it can be seen that some improvement was noted, but not as much as had been expected. From these results, ideas of how to improve the IL program have been gleaned and will now be implemented in sessions going forward. This research can also be used to provide evidence to nursing faculty on the improvement of both confidence to begin evidenceinformed practice and actual information literacy skills as an indication of value of curriculum-based IL instruction.

\section{References}

1. Presidential committee on information literacy: Final report. Washington, D.C.: Association of College and Research Libraries; 1989.

2. Competency Development Working Group. Nursing informatics entry-to-practice competencies for registered nurses. Ottawa, ON: Canadian Association of Schools of Nursing; 2012

3. Bundy A. Australian and New Zealand information literacy framework: Principles, standard and practice. 2nd ed. Adelaide: Australian and New Zealand Institute for Information Literacy; 2004.

4. Owusu-Ansah E. Information literacy and higher education: Placing the academic library in the center of a comprehensive solution. J Acad Libr. 2004;30(1):3-16. doi: 10.1016/j.jal. 2003.11.002.
5. Barnard A, Nash R, O'Brien M. Information literacy: Developing lifelong skills through nursing education. $J$ Nurs Educ. 2005;44(11):505-10.

6. Carlock D, Anderson J. Teaching and assessing the database searching skills of student nurses. Nurse Educ. 2007; 32(6):251-5. doi: 10.1097/01.NNE.0000299477.57185.ba.

7. Lalor J, Clarke M, Sheaf G. An evaluation of the effectiveness of information literacy training for undergraduate midwives to improve their ability to access evidence for practice. Nurse Educ Pract. 2012;12(5):269-72. doi: 10.1016/ j.nepr.2012.06.005

8. Jacobs SK, Rosenfeld P, Haber J. Information literacy as the foundation for evidence-based practice in graduate nursing education: A curriculum-integrated approach. J Prof Nurs. 2003;19(5):320-28. doi: 10.1016/S8755-7223(03)00097-8.

9. Cullen R, Clark M, Esson R. Evidence-based informationseeking skills of junior doctors entering the workforce: An evaluation of the impact of information literacy training during pre-clinical years. Health Info Libr J. 2011;28(2):1192. doi: 10.1111/j.1471-1842.2011.00933.x.

10. Beck S, Blake-Campbell B, McKay D. Partnership for the advancement of information literacy in a nursing program. Community Jr Coll Libr. 2012;18(1):3-11. doi: 10.1080/ 02763915.2012 .651957$.

-11. Kroth PJ, Phillips HE, Eldredge JD. Leveraging change to integrate library and informatics competencies into a new CTSC curriculum: A program evaluation. Med Ref Serv $Q$. 2009;28(3):221-34. doi: 10.1080/02763860903069888.

12. Brettle A. Evaluating information skills training in health libraries: A systematic review. Health Info Libr J. 2007;24:1837. doi: 10.1111/j.1471-1842.2007.00740.x.

13. Craig A, Corrall S. Making a difference? Measuring the impact of an information literacy programme for preregistration nursing students in the UK. Health Info Libr J. 2007;24(2):118-27. doi: 10.1111/j.1471-1842.2007.00688.x.

14. Wallace MC, Shorten A, Crookes PA. Teaching information literacy skills: An evaluation. Nurse Educ Today. 2000;20(6):485-9. doi: 10.1054/nedt.1999.0439.

15. Verhey MP. Information literacy in an undergraduate nursing curriculum: Development, implementation, and evaluation. J Nurs Educ. 1999;38(6):252-9.

16. Tarrant M, Dodgson JE, Law BV. A curricular approach to improve the information literacy and academic writing skills of part-time post-registration nursing students in Hong Kong. Nurse Educ Today. 2008;28(4):458-6. doi: 10.1016/ j.nedt.2007.08.001.

17. Kleyman EZ, Tabaei S. Information literacy needs in graduate-level health sciences education. J Physician Assist Educ. 2012;23(2):36-41.

18. Jacobsen HE, Andenæs R. Third year nursing students' understanding of how to find and evaluate information from bibliographic databases and internet sites. Nurse Educ Today. 2011;31(8):898-903. doi: 10.1016/j.nedt.2011.01.003.

19. Burkhardt JM. Assessing library skills: A first step to information literacy. Portal Libr Acad. 2007;7(1):25-49. doi: 10.1353/pla.2007.0002. 
20. Gilman IP. Evidence-based information-seeking behaviors of occupational therapists: A survey of recent graduates. J Med Libr Assoc. 2011 10;99(4):307-10. doi: 10.3163/1536-5050.99.4.009.

21. Diller KR, Phelps SF. Learning outcomes, portfolios, and rubrics, oh my! Authentic assessment of an information literacy program. Portal Libr Acad. 2008;8(1):75-89. doi: 10.1353/pla.2008.0000.

22. Franks H, McAlonan C. Establishing library 'key skill' confidence levels amongst a cohort of nursing students at an english university. Nurse Educ Pract. 2007;7(4):258-65. doi: 10.1016/j.nepr.2006.08.001.

23. Hodgens C, Sendall MC, Evans L. Post-graduate health promotion students assess their information literacy. Ref Serv Rev. 2012;40(3):408-22. doi: 10.1108/00907321211254670.

24. Özkul H, Kaya H. The views of nursing students about their own information literacy. New Educ Rev. 2009;19(3):45-57.

25. Turnbull B, Royal B, Purnell M. Using an interdisciplinary partnership to develop nursing students' information literacy skills: An evaluation. Contemp Nurse. 2011;38(1):122-9. doi: 10.5172/conu.2011.38.1-2.122.

26. Ku YL, Sheu S, Kuo SM. Efficacy of integrating information literacy education into a women's health course on information literacy for RN-BSN students. J Nurs Res. 2007;15(1):67-7.

27. Position statement: Evidence-informed decision-making and nursing practice. Position Statement. Ottawa, ON: Canadian Nurses Association; 2010. Report No.: PS-113.
28. Kruger J, Dunning D. Unskilled and unaware of it: How difficulties in recognizing one's own incompetence lead to inflated self-assessments. J Pers Soc Psychol. 1999;77(6): 1121-34. doi: 10.1037/0022-3514.77.6.1121.

29. Simons DJ. Unskilled and optimistic: Overconfident predictions despite calibrated knowledge of relative skill. Psychon Bull Rev. 2013;24. doi: 10.3758/s13423-013-0379-2.

30. Stankov L, Lee J, Paek I. Realism of confidence judgments. Eur J Psychol Assess. 2009;25(2):123-30. doi: 10.1027/10155759.25.2.123.

-31. Gross M, Latham D. Attaining information literacy: An investigation of the relationship between skill level, selfestimates of skill, and library anxiety. Libr Inform Sci Res. 2007;29(3):332-53. doi: 10.1016/j.lisr.2007.04.012.

32. Gross M, Latham D. What's skill got to do with it?: Information literacy skills and self-views of ability among first-year college students. $J$ Am Soc Inf Sci Tec. 2012;63(3):574-83. doi: 10.1002/asi.21681.

33. Distance education, learning and teaching support (DELTS): Instructional development office. In: Memorial University Calendar 2013-2014. St. John's, Newfoundland and Labrador: Memorial University of Newfoundland; 2013. p. 37.

34. Bragg, E, Hajek, A. Learning objectives: The cognitive domain. Workshop handout. St. John's, NL: Instructional Development Office, Memorial University of Newfoundland; 2000 . 


\section{Appendix A}

\section{BN Information Literacy Questionnaire - (Fall 2011)}

1. Please Respond to the following statement before completing the survey:

"I expect to graduate in spring or fall 2012"

O YES

O NO

2. How prepared do you feel you are to begin evidence-informed practice in a clinical setting?

O very unprepared O Somewhat unprepared O Somewhat prepared O very prepared

3. If you selected either "somewhat prepared" or "very prepared" in question \#2, what experiences from your four years of nursing prepared you for evidence-informed practice? Please describe:

4. What could we have done that we didn't do to better prepare you for evidence-informed practice?

5. Please rank your confidence in your ability to perform the following actions:

$\begin{array}{lcccc}\begin{array}{l}\text { Not at all } \\ \text { Renfident } \\ \text { studies }\end{array} & \begin{array}{c}\text { Not quite } \\ \text { confident }\end{array} & \begin{array}{c}\text { Somewhat } \\ \text { confident }\end{array} & \begin{array}{c}\text { Very } \\ \text { confident }\end{array} \\ \begin{array}{l}\text { Selecting and evaluating resources for } \\ \text { patient use }\end{array} & 0 & 0 & 0 & 0 \\ \begin{array}{l}\text { Efficiency in searching for and locating } \\ \text { evidence-based literature } \\ \begin{array}{l}\text { Identifying and knowing when to use } \\ \text { different research study types }\end{array}\end{array} & 0 & 0 & 0 & 0\end{array}$

6. You are doing research to find out how adolescent attitudes toward risk-taking affect recreational drug use. You have already searched CINAHL.

Where would you look next to find more scholarly research articles on your topic? Name two databases:

1.

2. 
7. Indicate whether each of the following statements is true or false: Medical Subject Headings are useful because they...

...are used in all healthcare databases.

True False

...are comprehensive, retrieving everything on that subject, regardless of the terminology used in the article.

...are specific, retrieving only things that are about that subject, and avoiding things that mention your terms in passing or use them in a different way.

...provide a quick and easy way to find a few useful articles.

$\mathrm{O}$

O $\quad 0$

$0 \quad 0$

$0 \quad 0$

8. Name three characteristics of a scholarly, research-based study.

2

3

9. You are searching for information to answer a therapyłype question (e.g. "Is St. John's wort as effective as traditional antidepressants for treating moderate depression?"). What is the best kind of study to look for?

Cohort study

Randomized controlled trial

Cross sectional study

Case control study

O Not sure

10. Beside each item, indicate whether it would be better to use a popular/trade or a scholarly/research source for this purpose:

A patient asks you to recommend some information that will help him Popular/ Scholarly/ Trade Research to better understand his medical condition.

You are trying to decide between two different approaches for treating

O a patient, and want to find out which one has the better patient outcome.

You are preparing a proposal for a new way of preventing medication errors, and are seeking evidence to support your arguments.

You are looking for a source that will help you keep up-to-date on the latest trends in your profession.

11. A cross sectional study is:

A study to determine prevalence and (or) distribution of a disease in a population.

A study where participants are randomly allocated to receive one of two or more interventions.

A study of a certain outcome among different groups of people who are similar in all but one characteristic.

A statistical technique which combines the results of several studies that ask the same or similar research questions. 
12. From the following case, identify each of the PICO components:

"A sexually active 17 year old female comes to you with questions about birth control. She is very concerned about getting pregnant and tells you she has a friend who got pregnant while on the pill. She is wondering if she should be using Depo-Provera instead. You decide to search the literature to see which is more effective."

P

।

C

$\mathrm{O}$

13. Now, using the case given in question $\# 12$, compose an answerable question you might use to guide your search:

14. Read each of the following questions and identify the question type:

Therapy Diagnosis Prognosis Etiology Not

"In children who are exposed to
passive smoking, what is the risk
of developing respiratory
disease?"
"In a patient with suspected
$\begin{aligned} & \text { cholecystitis, which test should be } \\ & \text { ordered: an utrasound or a } \\ & \text { cholescintigraphy?" }\end{aligned}$

15. As a healthcare professional, which of the following resources is the best place to look for information on complementary or alternative treatments (e.g. Using Ginkgo, a herbal product, for treatment of sexual dysfunction)?

O Jamieson's Natural Products

eCPS

Natural Standard

O UptoDate

16. As a health care professional, which of the following resources is the best place to look for information on correct dosage for drugs approved for medical use in Canada?
Pfizer Canada
O eCPS
Natural Standard
O UptoDate 
17. You want to refer a patient to some reliable, straight-forward websites about type II diabetes. You have done a search and found several sites that you are thinking about recommending. Name three criteria that you would use to evaluate each site and decide if it is appropriate:

1.

2.

3.

18. Now, name three things that might lead you to decide NOT to use a website for the purpose described in \#17:

1.

2.

3.

19. Which of the following search statements will get the best results for the following topic: "What are the effects of touch therapy for premature infants?"

(effect* OR touch) AND (baby OR babies OR infant OR infants)

(baby OR babies OR infant*) AND (preterm OR premature) AND touch

O touch AND pre* AND (bab* OR infant*)

$O$ touch therapy AND premature OR (baby AND babies AND infant*)

20. OPTIONAL: Thank you for participating in our study! If you would like to enter a draw to win one of our great prizes (each prize consists of a gift certificate to Mark's Work Wearhouse and a nursing watch), please submit your name and email address:

Name:

Email Address: 